\section{An industry perspective on pain treatment in the UK}

Jan-Uwe Claas' and Mark Suett ${ }^{1}$ speak to Henry Ireland, Senior Drug Evaluations Editor: Dr Jan-Uwe Claas, General Manager, Grünenthal UK Ltd, and Dr Mark Suett, Interim Medical Director, discuss Grünenthal's role in pain management, the current barriers to improving treatment in the UK and the supporting role the company plays in advancing this field. Grünenthal UK Ltd is a subsidiary of Grünenthal GmbH, based in Aachen, Germany.

First draft submitted: 22 November 2016; Accepted for publication: 5 December 2016; Published online: 7 February 2017

\section{Q What are the main areas in pain management that Grünenthal are working on? \\ - Jan-Uwe Claas}

We produce treatments for acute moderate to severe pain, severe chronic pain, acute moderate to severe postoperative pain and postherpetic neuralgia. By targeting these key areas, we aim to provide real benefits to patients.

\section{- Mark Suett}

At Grünenthal, when we think about managing pain, the quality of life of the patient is of upmost importance. Our ambition is therefore to produce effective medications that also minimize the side-effect burden. We know from our discussions with patients and healthcare professionals (HCPs) that sometimes the side-effect burden of pain-relieving medications can be a significant problem.

\section{- Jan-Uwe Claas}

To give an example, constipation is a debilitating side effect that many chronic pain patients have to endure. It can have a major impact on their daily life and might lead to social isolation and job loss. If a treatment is available, which is cost effective, and offers an improved side-effect profile as well as improved quality of life, then it is of course of considerable benefit for patients and the health service. It has the potential to save National Health Service (NHS)'s costs and reduce the impact on the economy from working days lost.

\section{- Mark Suett}

There is a balancing act between effective pain management and optimizing quality of life at the same time.

\section{Q What is Grünenthal's current place in the pain management market?}

\section{- Jan-Uwe Claas}

We provide a number of products licensed in this market. These include tapentadol for acute and chronic pain; the lidocaine plaster, Versatis, for the symptomatic relief of neuropathic pain associated with previous herpes zoster infection (postherpetic neuralgia) in adults; and we also have a new product for postoperative pain in a hospital setting which is currently in the launch phase. We also distribute Arcoxia, an NSAID, for the symptomatic relief of osteoarthritis and rheumatoid arthritis, which is part of an in-licensing agreement.

Working with partners in the pain field is an important part of our business strategy. We enjoy a leading position in the UK
KEYWORDS

- acute pain • chronic pain • pain management
Future
Medicine isg 
market as a pain management specialist and, as a company, we continue to expand our portfolio into adjacent areas. Of course, we continue to be committed to improve pain management by discovering new and innovative analgesics.

Indeed, R\&D is at the core of Grünenthal's business, and we continue to invest substantially into $\mathrm{R} \& \mathrm{D}$. We have recently opened a new research center at our main location in Germany where we carry out preclinical research. We are also working in collaboration with other well-established research centers.

\section{- Mark Suett}

Pain, particularly chronic pain, can have a complex etiology and can therefore be complex to manage. Patients need a variety of approaches to manage their pain, both in terms of the medicinal product and the route of administration that is utilized in delivering that medicine.

We are now looking beyond just chronic pain or acute pain and are looking into areas where an even more specialized approach is required.

\section{Q Grünenthal is undertaking a number of} initiatives in pain management. Can you tell us about the Change Pain ${ }^{\circledast}$ initiative?

\section{- Jan-Uwe Claas}

In recent years, pain management has certainly become a more prominent topic on the health agendas of a number of European governments - although we recognize that policymakers, and also HCPs, particularly in the UK, may need more support.

Consequently, to support HCPs, we developed the Change Pain medical education program, a European-wide initiative, which is product independent and governed by a team of international experts. In the UK, we offer this as an online learning tool for HCPs.

Change Pain is free and endorsed by the European Pain Federation and is CME accredited. It involves a huge commitment from Grünenthal, and involves a major investment of time and resources - and we are continually looking at how it can be expanded and developed further.

\section{- Mark Suett}

And remember, we are not a large pharmaceutical company. I think, more than anything Change Pain demonstrates our commitment to making a meaningful difference to pain management. We are very proud of it.
Q What are the barriers for the management of pain in the UK?

\section{- Jan-Uwe Claas}

Policymakers often fail to recognize that pain management is a distinct speciality. For example, pain theoretically sits within the remit of several NHSE National Clinical Directors, but has never had one of its own. A lack of focus among policymakers means that pain tends to be neglected.

Further pressures come as a result of financial constraints - especially given the NHS budget restraints in primary care. Waiting lists in pain clinics can stretch from months to years. Then there is limited access to what you can actually use to treat the pain - normally a small number of drugs with a potentially significant side-effect burden.

\section{- Mark Suett}

Pain is a significant public health burden that comes under greater stress if budgets are tightened and resources are stretched. A 2011 survey showed that almost one in four patients with persistent chronic pain said that their pain had kept them from usual activities - including work. A substantial proportion of patients are seeing their quality of life reduced.

In a National Pain Audit, $20 \%$ of the respondents reported visiting accident and emergency in the past 6 months; all of them had previously seen their GP, which is of course a further burden to the NHS.

Chronic pain is complicated to deal with from a clinical perspective. There may not be anything abnormal on the blood test, or the x-ray. We are not 'programmed' to see chronic pain as a disease. Although that has changed to some degree since I was at medical school, there is still a lot of work to be done.

\section{- Jan-Uwe Claas}

Yes, chronic pain is difficult to deal with. For example, if a patient is given some kind of pain relief, it is impossible to know what is happening after they go home without having regular reviews with the GP.

Perhaps the patient takes the medication, experiences side effects quickly and then stops taking it. We found that less than 50\% of patients prescribed strong opioids were still taking their medication after 4 weeks.

Further research suggests some patients stop medication even earlier than this. A common 
patient response is "why has the doctor given me this medication? Why do I have to take it when it makes me feel worse?" It is essential that the patient's response to pain-relieving medication is reviewed and optimized.

\section{- Mark Suett}

Without this, patients with chronic pain can sometimes be forced to access the health service through less than ideal routes, such as presenting to $A \& E$.

\section{- Jan-Uwe Claas}

Yes. They go to A\&E and enter a different system. Communication between the different parts of the NHS can be less than ideal, and this can have a negative impact on a patient's treatment. A\&E attendance rates continue to rise and this is a significant issue for the NHS.

\section{- Mark Suett}

Pain is a universal symptom, and is often the reason why a patient presents to an HCP. But unfortunately, in our work we have seen examples where pain management is not optimal.

\section{Q Do problems associated with pain} treatment need to be better reported in the media?

\section{- Jan-Uwe Claas}

Coming from Germany, I often see reports on the issues relating to chronic pain treatment on a regular basis in the German media. I do not know why this is, but I have not seen similar reports in the UK press during my 5 years here.

\section{- Mark Suett}

Yes, news about pain in the UK seems to be more focused on the abuse or misuse of painrelieving medication. That is another area that Grünenthal has focused on, for example, the development of tamper-resistant technology.

\section{- Jan-Uwe Claas}

That is just one side of the story. When developing a pain treatment, you have to provide abuse data to the US FDA before approval. Studies suggest that some next-generation pain killers may have lower abuse figures. The reason for this is very simple - they do not have the same side effects sought after by some users. This is where our innovation comes in. It is about thinking around the problem. This is what Grünenthal is good at.

\section{- Mark Suett}

In my opinion, pain management, particularly the management of chronic pain, does not have enough focus. It contrasts sharply with other disease areas such as oncology or diabetes, which have achieved a considerable volume of media attention.

Chronic pain is not very 'exciting' from a media perspective but the impact from not treating it adequately is immense. If you take into account the number of working days lost and the reduced quality of life, the economic and social repercussions of pain are far reaching and costly.

Q How is Grünenthal supporting scientists in the field of pain?

\section{- Mark Suett}

Through education Change Pain seeks to engage with HCPs in order to make a meaningful difference. That is what our Pain Awards are about too.

The program and the awards underline Grünenthal's commitment to the UK pain management community. We understand the need to fund and support innovation in clinical practice, whether that is a small community project, to something broader and more academic, based in a large teaching hospital.

There is also a European program; the E-G-G initiative. For this, we offer the European Pain Federation - Grünenthal Grant, a biannual research prize aimed at young scientists. The grant is focused on research and provides significant funding for European projects.

\section{- Jan-Uwe Claas}

To some degree we were surprised by the interest and success of the Grünenthal Pain Awards. Those HCPs whose innovation had been acknowledged in the awards, would go back into the NHS and be told "yes, this is a fantastic project, so we will give you multiple times the amount of money to run your project for us." This is what makes us so proud. Seeing the success stories of the previous years is very rewarding, you see how the project has developed into something extraordinary. Some of the winners have said this is career shaping for them.

\section{- Mark Suett}

It is important to stress that Grünenthal does not make the award decisions. We have a group of independent experts to judge and hand over the awards, and we are continually developing the format. For example, we recently invited a patient on to the judging panel, who is interesting 
because they have a completely different perspective to the other judges. For the winners, the Grünenthal Pain Awards are motivating. It is about being recognized for what they have achieved. The recognition for the work they have done has been as important as the financial value of the award. Although the financial award is also important since this allows them to develop their projects even further.

Q How do you see Grünenthal's role in pain management in 10 years' time?

- Jan-Uwe Claas

We would like to keep our innovation and our specialty status. So we will never abandon the field, and this is part of the real advantage of being a privately owned company - we do not have to constantly appease shareholders. We have a good, long-term relationship with our customers.

We will continue our journey and our agenda will remain the same - to ensure as best we can that all patients are managed appropriately.

Q Do you have any closing remarks for our readers?

- Mark Suett

Just to reiterate that we are passionate about providing tangible treatment benefits to people living with chronic and acute pain.

\section{- Jan-Uwe Claas}

We have to find a way to work with the NHS to bring pain more clearly onto the agenda - to emphasize how important it is to treat patients in the right way.

Currently, there are too many patients whose quality of life is being impaired by poor treatment. This must change.

\section{Disclaimer}

The opinions expressed in this interview are those of the interviewees and do not necessarily reflect the views of Future Medicine Ltd.

Financial \& competing interests disclosure $J U$ Claas and M Suett are employees of Grünenthal UK Ltd. Grünenthal UK Ltd owns rights to products discussed within this interview. JU Claas and M Suett have no other relevant affiliations or financial involvement with any organization or entity with a financial interest in or financial conflict with the subject matter or materials discussed in the manuscript apart from those disclosed.

No writing assistance was utilized in the production of this manuscript. 